http://jmscr.igmpublication.org/home/ ISSN (e)-2347-176x ISSN (p) 2455-0450

crossref DOI: https://dx.doi.org/10.18535/jmscr/v9i7.19

Journal Of Medical Science And Clinical Research

IGM Publication

An Official Publication of IGM Publication

\title{
Clinical patterns of Cerebral palsy in children who underwent serial casting for improvement in mobility at a tertiary care centre
}

Authors

\section{Sudhir Ravindran ${ }^{1}$, George Zachariah ${ }^{2}$, Padmakumar $\mathbf{G}^{3}$, Jijo Varghese ${ }^{4}$}

${ }^{1}$ Associate Professor, Department of Orthopaedics, Government Medical College, Thiruvananthapuram, Kerala, India

${ }^{2}$ Additional Professor CAP, Department of Physical Medicine and Rehabilitation Government Medical College,

Thiruvananthapuram, Kerala, India

${ }^{3}$ Assistant Professor, Department of Physical Medicine and Rehabilitation Government Medical College,

Thiruvananthapuram, Kerala, India

${ }^{4}$ Senior Resident, Department of Physical Medicine and Rehabilitation Government Medical College,

Thiruvananthapuram, Kerala, India

Corresponding Author

Sudhir Ravindran

Associate Professor, Department of Orthopaedics, Government Medical College, Thiruvananthapuram, Kerala, India

\begin{abstract}
Introduction and Rationale: Tone and movement abnormalities are the major impairments in Children with Cerebral palsy. The various clinical patterns of tone and movement abnormalities in children with Cerebral palsy include Spasticity, Dyskinesia, Hypotonia, Ataxia, and Dystonia. These clinical patterns also affect the limbs and trunk in different proportions. Serial Casting with plaster of Paris is one of the few interventions used for improving movement dysfunction and tone in children with cerebral palsy. Very little data is available describing the various patterns and its topographical involvement in such children who undergo serial casting for improvement in movement dysfunction and tone abnormality. The aim of this study is to describe the proportion of various clinical patterns of cerebral palsy in children who underwent serial casting for improvement in mobility.

Methodology: Retrospective data of clinical patterns of Cerebral palsy and its topographic distribution in 145 children who underwent serial casting at a tertiary care centre in India from 2016 to 2019 were compiled. This data was entered into a proforma after maintaining confidentiality of the patient and after Institutional Ethical committee clearance. This data was analysed for demographic data, proportions of clinical patterns of cerebral palsy and the topographic distribution of the impairments. This is a retrospective, descriptive, record based census type study.

Results \& Discussion: Data of 145 children with cerebral palsy were studied. The mean age was 5.8 yrs. Majority of them belonged to the 2 to 6 age group (66.9\%). About $58.6 \%$ of the study subjects were males and $41.4 \%$ were females. Similar to other studies, majority (93.8\%) of the children with CP had hypertonia and the rest had hypotonia. The prevalence of various types of tone and movement abnormalities were as follows. Most of the children had spasticity (93.1\%), 6.2\% had dyskinesia, 3.4\% had hypotonia, $2.8 \%$ had ataxia and $1.4 \%$ had dystonia. Diplegia accounted for $57.9 \%$ of the children and $15.2 \%$ had tetraplegia/quadriplegia. $11 \%$ had total body involvement. Most of the children with hemiplegia had involvement of the right side (73.3\%) and $26.7 \%$ had left side involvement.

Conclusion: Majority of the children with cerebral palsy who underwent serial casting had hypertonia. $93.1 \%$ of the children had spasticity, $6.2 \%$ had dyskinesia, 3.4\% had hypotonia, $2.8 \%$ had ataxia and only $1.4 \%$ had dystonia. $11.7 \%$ of the children had a mixed pattern of movement dysfunction. $57.9 \%$ of the children had diplegia, and $15.2 \%$ had tetraplegia and $11 \%$ had total body involvement. All of the children who had hemiplegia had spasticity only. Majority of the children with mixed pattern of CP had either tetraplegia or total body involvement.

Keywords: Cerebral palsy, prevalence, proportion, type of CP, spasticity, ataxia ,dyskinesia, hypotonia, dystonia, hemiplegia, diplegia, quadriplegia, total body involvement.
\end{abstract}




\section{Introduction \& Rationale}

Cerebral palsy is defined as a disorder of movement and posture due to a lesion in the immature brain ${ }^{1}$. Based on tone Cerebral palsy is classified into Spastic, Dyskinetic, Ataxic, Hypotonic and Mixed. Spastic CP is the commonest $^{2}$. Cerebral palsy is the leading cause of locomotor disability in children ${ }^{3}$. It affects approximately 2.11 live births worldwide ${ }^{4}$. Among the different types of $\mathrm{CP}$, spastic $\mathrm{CP}$ is the most common form consisting of approximately $85 \%$ of the diagnoses ${ }^{5}$. Rate of Cerebral palsy within the collaboration of $\mathrm{CP}$ registers in Europe varied from 1.5 to 3 per 1000 live births for the period between 1980 to $1996(n=9128)$. The proportion of various clinical patterns of $\mathrm{CP}$ in the above cohort is as follows. $53.9 \%$ of the $\mathrm{CP}$ children had bilateral spasticity, $31 \%$ had unilateral spasticity, $6.6 \%$ were of the dyskinetic variety and only $4.1 \%$ had ataxia ${ }^{17}$. The proportion of children who were unable to walk even with aids was $30.3 \%$.

One of the major impairments in children with cerebral palsy is movement dysfunction. Causes for movement dysfunction include spasticity, lower limb deformity, dyskinesia, hypotonia and ataxia among other factors. Standing balance and gait are affected in such children having lower limb deformity. Without appropriate management, spasticity may contribute to the onset of contractures of the muscles, ligaments and tendons ${ }^{6,7}$ affecting loading biomechanics and causing major functional limitations ${ }^{8}$. Current clinical management of spasticity and contracture in the lower limb includes conservative approaches such as the use of physiotherapy, orthoses, casting and splinting 9 . To correct the deformity and improve standing and gait various measures or interventions like, anti spastic drugs, injections, orthoses, exercise training, balance exercises, surgery for muscles, nerves and bones and serial casting with plaster of Paris are applied in various combinations. Several authors from studies cited in two systematic reviews ${ }^{10,11}$ recommended that serial casting be used to improve passive range of motion at the ankle to enhance functional outcomes in children with CP. In 2007, Blackmore and colleagues published a systematic review, reporting on limited evidence which suggested that serial casting is more effective in the management of secondary complication of CP than no serial casting ${ }^{12}$. Serial casting is commonly referred to as the application of two or more successive fibreglass or plaster casts to a particular joint with efforts to increase passive range of motion (PROM) around a joint by maintaining prolonged passive stretch in the submaximal or maximal range ${ }^{12,13}$. S Jain et al describes serial casting as a very simple, safe and cost effective procedure which can be applied even in children with mental sub normality having all three major joints involved bilaterally ${ }^{14}$. Though classically plaster of Paris casting is done to stretch the gastrosoleus muscle in children with cerebral palsy, walking casts also reduces tone, improves balance and functional mobility in children with cerebral palsy by stabilising the ankle joint during gait training. $S$ Jain et al also mentions that serial casting ultimately improved the ambulatory status and functional ability of these children ${ }^{14}$. These evidences regarding the effects of serial casting on lower limb function warrants further research into the subject.

Many children undergo serial casting with plaster of Paris to improve tone, deformity and mobility at the special clinic for children with cerebral palsy at the Dept of Physical Medicine and Rehabilitation of a tertiary care centre in the State of Kerala, India.

This study aims to describe the proportion of various types of cerebral palsy and its topographic distribution in those children who underwent serial casting as a part of the rehabilitation and orthopaedic intervention at this tertiary care centre. This study sheds light on the current trends of clinical patterns of tone \& movement abnormalities and its topographic distribution in the above cohort of children. 


\section{Objective}

To study the proportion of various types of cerebral palsy and its topographic distribution in children with cerebral palsy who underwent serial casting at the tertiary care centre of the study setting.

\section{Study Population}

Clinically diagnosed children with Cerebral palsy belonging to the age range of 2 years to 18 years who underwent serial casting for improvement in mobility at the Department of Physical Medicine and Rehabilitation, Medical College, Thiruvananthapuram, Kerala, India, during the period of study.

\section{Period of study}

The data available on the above cohort from January 2016 to December 2019 was compiled and processed during the first half of the year 2021.

\section{Study Design}

Retrospective, descriptive, record based, census type cohort study.

\section{Inclusion Criteria}

1. Children with various types of cerebral palsy

2. Children who underwent serial casting for rehabilitation and improvement in mobility

3. Age 2 years to 18 years

\section{Exclusion Criteria}

1. Data of children above 18 years and below 2 years

2. Children with severe seizures

3. Children having unstable medical conditions

4. Children with other musculoskeletal disorders like arthrogryposis multiplex congenital, congenital limb deficiencies, fractures etc.

5. Children who underwent casting of their limbs for fractures or injuries

\section{Methodology}

Retrospectively data from the period January 2016 to December 2019 of children with cerebral palsy who underwent serial casting, was collected from the Medical Records and Procedure register at the Dept of Physical Medicine \& Rehabilitation of the tertiary care centre after clearance from the Institutional Research Board and Human Ethics Committee. Only subjects with complete data satisfying the Inclusion criteria were included in the study cohort. Consecutive sampling of the subjects were taken and data was entered into a proforma including age, sex, diagnosis - type of clinical pattern of $\mathrm{CP}$ according to the tone and movement dysfunction, topographic involvement and type of lower limb casting given during the first visit, taking care to avoid the name and identification of the patient.

\section{Sampling Technique \\ Consecutive Sampling \\ Study Variables}

Age, gender, type of cerebral palsy according to tone \& movement abnormality (spasticity, dyskinesia, ataxia, hypotonia and dystonia), topographic distribution of the clinical pattern in the child (monoplegia, diplegia, triplegia, tetraplegia and total body involvement), type of casting at the first visit.

Monoplegia -only one limb is affected usually an arm

Hemiplegia -one side of the body is affected the arm is usually more affected than the leg

Diplegia - All four limbs are affected both legs are more affected than the arm

Quadriplegia- All four limbs are involved (In this study both quadriplegia and tetraplegia are synonymous)

Triplegia -Three limbs are involved.

Most of the topographic classification is based on the classification as described in "a guide to Cerebral palsy by the Ontario federation for CP20. However the current study has also included "Total body involvement" when both arms, legs, neck and head are also involved. 
Mixed type - when areas of the brain that control both muscle \& voluntary movement are affected a diagnosis of mixed was given, usually spasticity is more obvious at first with involuntary movement increasing as the child develops.

Spastic CP- is the most common type and is caused by injury to the motor cortex (increase in tone of the affected limb).

Ataxia - Unsteady standing or walking and balance problem, ataxia results from damage to the cerebellum.

Dystonia - twisting movements and positions of trunk and limbs20.

Dyskinetic - abnormal pattern of posture and or movement, involuntary uncontrolled recurring, occasionally stereotype movements 16 .

Serial casting- the application of two or more successive fibreglass or plaster casts to a particular joint with efforts to increase passive range of motion (PROM) around a joint by maintaining prolonged passive stretch in the submaximal or maximal range 12,13 .

\section{Study Procedure}

Data of 229 children with Cerebral palsy were obtained from the medical records of the study setting during the years 2016 to 2019. 145 out of 229 children satisfied the inclusion criteria and had complete data of the study variables mentioned. Data of these 145 children were included in the study cohort. The data that was collected and compiled was subjected to statistical analysis.

\section{Statistical Analysis}

Data of 145 children who satisfied the inclusion criteria which was collected using the proforma was further compiled and entered into an Excel Sheet and subjected to appropriate statistical analysis by an expert Statistician. Quantitative data like age was expressed as mean and grouped into a range, qualitative data like gender, type of clinical pattern of Cerebral palsy, topographic distribution and side of involvement were expressed as proportions. Each of the type of movement disorder was also analysed for the topographic distribution and expressed as proportions.

\section{Ethical Issues}

The study was conducted only after Institutional Review Board and Ethical committee approval and appropriate measures were taken to protect the identity of the subjects.

\section{Results \& Observation}

The study consisted of 145 children with various clinical patterns of cerebral palsy who underwent serial casting with plaster of Paris for improvement in mobility. These children received the plaster casting at a special clinic at the department of Physical Medicine and Rehabilitation of a tertiary care centre in the state of Kerala, India. The different types of clinical patterns included Spastic, Dyskinetic, Ataxic, Hypotonic, Dystonic and mixed varieties.

The children with cerebral palsy belonged to the ages of 2 to 18 years. Of the 145 subjects in the study group $58.6 \%$ were males and $41.4 \%$ were females. $93.8 \%$ of the study group had hypertonia and $6.2 \%$ had hypotonia.

\section{Background characteristics of patients}

Table No: 1 Percentage distribution of the sample according to age $\mathrm{n}=145$

\begin{tabular}{|l|c|c|}
\hline Age in years & Count & Percent \\
\hline $2-6$ & 97 & 66.9 \\
\hline $7-12$ & 36 & 24.8 \\
\hline$>12$ & 12 & 8.3 \\
\hline Mean \pm SD & $5.8 \pm 3.8$ & \\
\hline
\end{tabular}

Fig No : 1 . Percentage distribution of the sample according to age

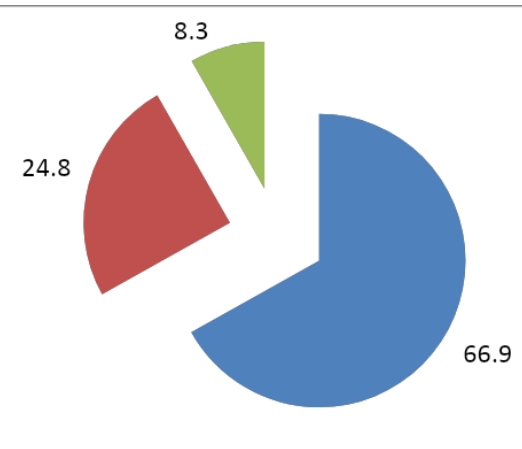

$2-6 \square 7-12 \square>12$ 
Of the 145 children with Cerebral palsy who underwent serial casting at the study setting $66.9 \%$ were of the age group 2 to 6 years. $24.8 \%$ belonged to the 7 to 12 age group and $8.3 \%$ were above 12 years but below 18 years (Table no:1).

Table no: 2 Percentage distribution of the sample according to gender $n=145$

\begin{tabular}{|l|c|c|}
\hline Gender & Count & Percent \\
\hline Female & 60 & 41.4 \\
\hline Male & 85 & 58.6 \\
\hline
\end{tabular}

Fig No: 2 Gender distribution of the study population

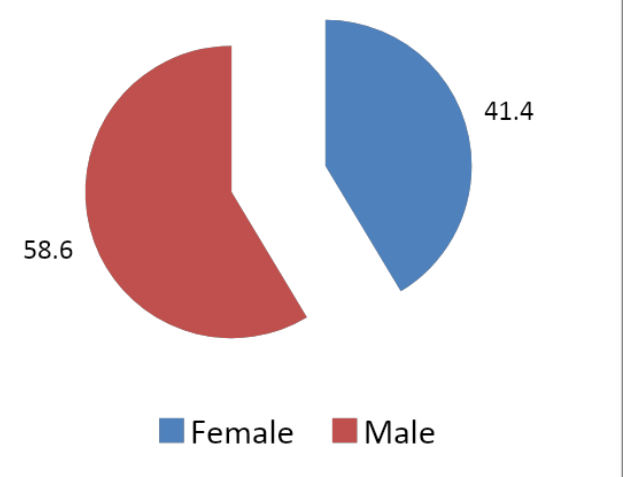

$(n=145) 58.6 \%$ of the study population were boys and $41.4 \%$ were girls (Table no:2)

\section{Clinical patterns of cerebral palsy}

Table no: 3 Percentage distribution of the sample according to tone

\begin{tabular}{|l|c|c|}
\hline Tone & Count & Percent \\
\hline Hypertonic & 136 & 93.8 \\
\hline Hypotonic & 9 & 6.2 \\
\hline
\end{tabular}

$(\mathrm{n}=145) \quad$ When the study population was categorized according to tone into hypertonia and hypotonia $93.8 \%$ had increased tone and only $6.2 \%$ had hypotonia. (Table no: 3 )

Table No 4 Percentage distribution of the sample according to type of Cerebral palsy

\begin{tabular}{|l|c|c|}
\hline Type of Cerebral palsy & Count & Percent \\
\hline Spastic & 135 & 93.1 \\
\hline Dyskinetic & 9 & 6.2 \\
\hline Ataxic & 4 & 2.8 \\
\hline Hypotonic & 5 & 3.4 \\
\hline Dystonic & 2 & 1.4 \\
\hline Mixed & 17 & 11.7 \\
\hline
\end{tabular}

Distribution of the children with CP $(n=145)$ according to the presence of tone and movement dysfunction (Type of clinical pattern of CP) revealed the following. Majority (93.1\%) had spasticity as the major movement dysfunction, $6.2 \%$ had dyskinesia, $3.4 \%$ had pure hypotonia, $2.8 \%$ had ataxia and only $1.4 \%$ had dystonia. (Table No: 4).

To Note: two or more clinical patterns of tone and or movement abnormality can be present in one child. These children were categorized into those children who had a mixed pattern of cerebral palsy.

However $11.7 \%$ of the study group had a mixed pattern of involvement.

Fig No: 3 percentage distribution of the study population according to the type of clinical pattern of Cerebral Palsy (tone \& movement dysfunction) $(n=145)$

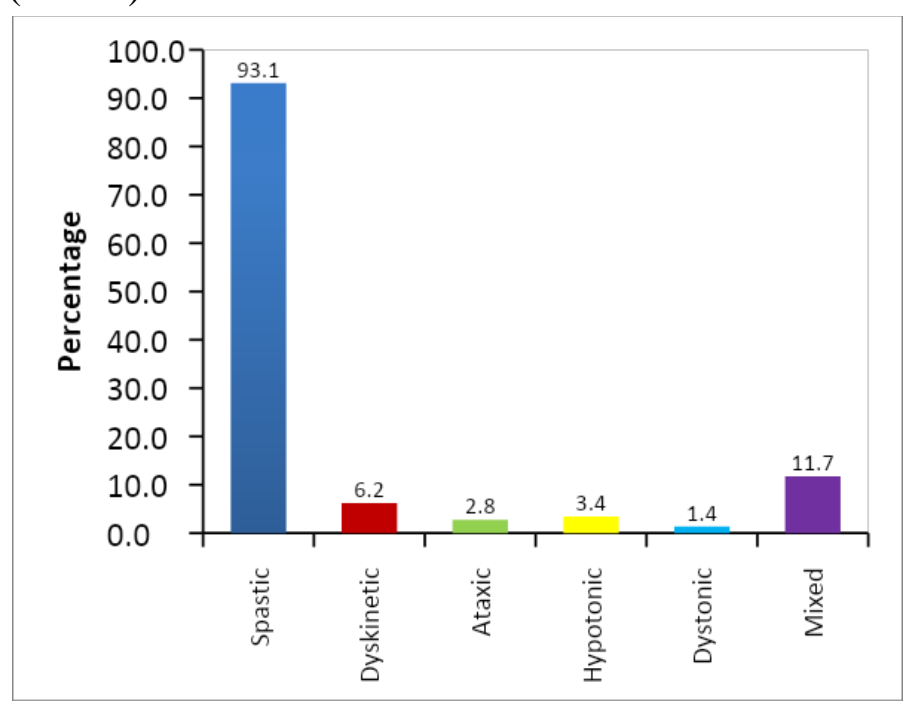

Table No: 5 Percentage distribution of the sample according to topographical distribution $(n=145)$.

\begin{tabular}{|l|c|c|}
\hline $\begin{array}{l}\text { Type of Cerebral palsy according to } \\
\text { topographic distribution }\end{array}$ & Count & Percent \\
\hline Hemiplegia & 15 & 10.3 \\
\hline Diplegia & 84 & 57.9 \\
\hline Triplegia & 8 & 5.5 \\
\hline Tetraplegia & 22 & 15.2 \\
\hline Total body involvement & 16 & 11.0 \\
\hline
\end{tabular}


Fig No: 4 Percentage distribution of the sample according to topographical involvement.

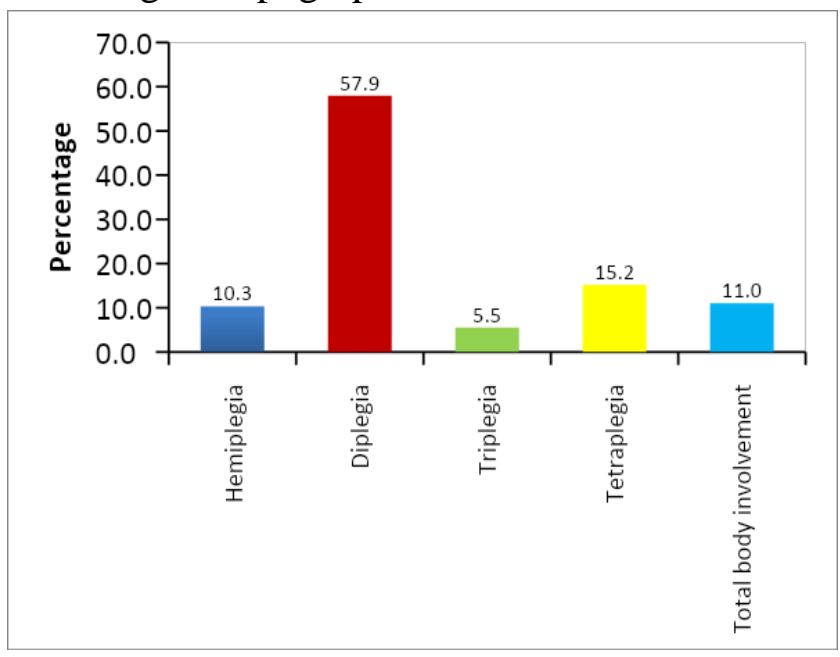

When the distribution of tone abnormality according to limb involvement (topographical involvement) of the study group was analysed, it revealed that $57.9 \%$ had diplegia, $15.2 \%$ had tetraplegia, $10.3 \%$ had hemiplegia, $11 \%$ had total body involvement and only $5.5 \%$ had triplegia. (TableNo:5).
Table No: 6 Percentage distribution of the sample according to side of hemiplegia $(n=15)$

\begin{tabular}{|l|c|c|}
\hline Side of hemiplegia & Count & Percent \\
\hline Right & 11 & 73.3 \\
\hline Left & 4 & 26.7 \\
\hline
\end{tabular}

In 15 children with hemiplegia most of them had right side involvement $(73.3 \%)$ and $26.7 \%$ had involvement of the left side.(Table No:6)

Table No: 7 Percentage distribution of the sample according to type of casting $(n=145)$

\begin{tabular}{|l|c|c|}
\hline Type of casting & Count & Percent \\
\hline Unilateral BK & 14 & 9.7 \\
\hline Bilateral BK & 87 & 60 \\
\hline Unilateral AK & 2 & 1.4 \\
\hline Bilateral AK & 31 & 21.4 \\
\hline Bilateral cylinder & 11 & 7.6 \\
\hline
\end{tabular}

At the first visit for serial casting of the 145 children studied, $60 \%$ of the subjects received bilateral below knee casting, $21.4 \%$ received bilateral above knee casting, $9.7 \%$ received unilateral below knee casting, $7.6 \%$ received bilateral cylinder casting and only $1.4 \%$ received unilateral above knee casting. (TableNo:7).

Table No: 8 Percentage Distribution of topographic involvement in each type (tone \&movement dysfunction) of Cerebral palsy.

\begin{tabular}{|c|c|c|c|c|c|c|c|c|c|c|}
\hline $\begin{array}{l}\text { Type of Cerebral } \\
\text { palsy }\end{array}$ & Hemiplegia & & Diplegia & & Triplegia & & Tetraplegia & & $\begin{array}{c}\text { Total body } \\
\text { involvement }\end{array}$ & \\
\hline & Count & Percent & Count & Percent & Count & Percent & Count & Percent & Count & Percent \\
\hline Spastic & 15 & 11.1 & 82 & 60.7 & 8 & 5.9 & 16 & 11.9 & 14 & 10.4 \\
\hline Dyskinetic & 0 & 0.0 & 2 & 22.2 & 0 & 0.0 & 2 & 22.2 & 5 & 55.6 \\
\hline Ataxic & 0 & 0.0 & 2 & 50.0 & 0 & 0.0 & 2 & 50.0 & 0 & 0.0 \\
\hline Hypotonic & 0 & 0.0 & 0 & 0.0 & 0 & 0.0 & 4 & 80.0 & 1 & 20.0 \\
\hline Dystonic & 0 & 0.0 & 0 & 0.0 & 0 & 0.0 & 1 & 50.0 & 1 & 50.0 \\
\hline Mixed & 0 & 0.0 & 2 & 11.8 & 1 & 5.9 & 4 & 23.5 & 10 & 58.8 \\
\hline
\end{tabular}

Fig No: 5 Percentage distribution of topographic involvement in each type of cerebral palsy $(n=145)$

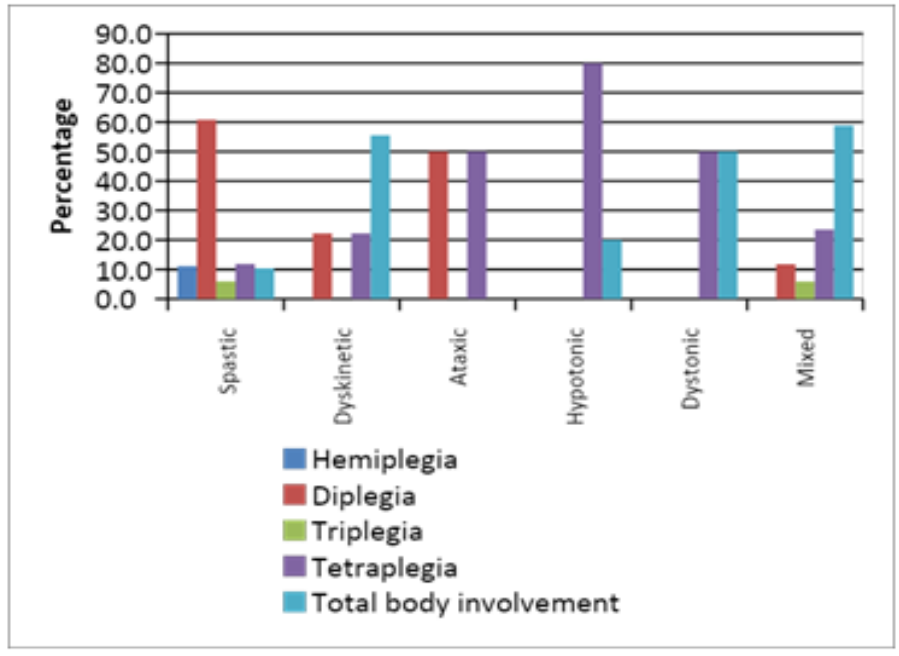


When the distribution of the topographical involvement was analysed in the different types of cerebral palsy according to tone \& movement dysfunction the following pattern unravelled. $60.7 \%$ of the children with spasticity had diplegia, $11.9 \%$ had tetraplegia, $10.4 \%$ had total body involvement and only $5.9 \%$ had triplegia. Among the children with dyskinesia majority (55.6\%) had total body involvement and $22.2 \%$ had tetraplegia and a similar percentage $(22.2 \%)$ had diplegia. Among the children with ataxia half $(50 \%)$ had diplegia and the rest (50\%) had tetraplegia. Among the children with hypotonia $80 \%$ had all four limbs involved (tetraplegia) and $20 \%$ had total body involvement. Among the children with dystonia 50\% had tetraplegia and 50\% had total body involvement but that was only in 2 subjects. Interestingly more than half $(58.8 \%)$ of the children with mixed type had total body involvement and $23.5 \%$ had tetraplegia. $11.8 \%$ had diplegia and only $5.9 \%$ had triplegia. (TableNo:8).

Table No: 9 Distribution of gender based on type of cerebral palsy $(n=145)$.

\begin{tabular}{|l|c|c|c|c|}
\hline Type of Cerebral palsy & Female & & Male & \\
\hline & Count & Percent & Count & Percent \\
\hline Spastic & 54 & 40.0 & 81 & 60.0 \\
\hline Dyskinetic & 5 & 55.6 & 4 & 44.4 \\
\hline Ataxic & 3 & 75.0 & 1 & 25.0 \\
\hline Hypotonic & 3 & 60.0 & 2 & 40.0 \\
\hline Dystonic & 2 & 100.0 & 0 & 0.0 \\
\hline Mixed & 10 & 58.8 & 7 & 41.2 \\
\hline
\end{tabular}

Of the study population $40 \%$ of the children with spasticity were females and $60 \%$ were males, of the children having dyskinesia $55.6 \%$ were females and $44.4 \%$ were males. $75 \%$ of the children with ataxia were females and $25 \%$ were males. $60 \%$ of the children with hypotonia were females and $40 \%$ were males. All of the children with dystonia were females. Of the children with a mixed pattern of cerebral palsy $58.8 \%$ were females and $41.2 \%$ were males. (Table No: 9 )

\section{Discussion}

Cerebral palsy is the leading cause of locomotor disability in Children ${ }^{3}$. It affects 2.1 per 1000 live births worldwide. Among the different types of cerebral palsy spastic cerebral palsy is the commonest, consisting of $85 \%$ of the diagnosis according to Australian CP Register 2018 report $^{5}$. Cerebral palsy rehabilitation is a comprehensive process where multiple interventions like exercise, drugs, orthosis, motor point blocks, serial plaster casting, physiotherapy, occupational therapy, speech therapy, surgery, etc. are provided for functional improvement in such children. Application of serial casting improves the range of motion of the joint, reduces muscle tone, improves balance and functional mobility according to $\mathrm{S}$ Jain et $\mathrm{al}^{14}$.

Many children with cerebral palsy undergo serial casting to reduce the above impairments at the Dept of Physical Medicine \& Rehabilitation of the study setting. Though most of the children who undergo serial casting have a spastic pattern a few have other movement dysfunctions like dyskinesia, ataxia and hypotonia in different proportions.

The aim of this study was to find the proportion of various types of clinical patterns in cerebral palsy in children belonging to the study group.

In this retrospective, descriptive, record based, census type cohort study, 145 children satisfied the inclusion criteria. Most of the children belonged to the 2 to 6 age group (66.9\%). $24.8 \%$ were between 7 and 12 years and only $8.3 \%$ were above 12 years of age. Gender wise $58.6 \%$ of the children were boys and $41.4 \%$ were girls which is similar to the findings from the Australian CP Register (2018) report which show that between 1995 \& 2012 of the 8164 children with CP, 57\% were males and $43 \%$ were females 21 . 
The data from the Australian CP registry report $(2018)^{5}$ revealed that $85 \%$ of the children with $\mathrm{CP}$ were of the spastic type. Similarly, majority of the children with $\mathrm{CP}$ in this study were also of the hypertonic type $(93.8 \%)$ and only $6.2 \%$ were hypotonic.

According to a recommendation by NINDS 2001 workshop on childhood hypertonia, many children have mixed presentations and that identifying the presence of each of the tone and movement abnormality may be of clinical utility ${ }^{1}$. The Surveillance of CP in Europe divides CP into 3 groups based on the predominant neuromotor abnormality namely -Spastic, Dyskinetic, and Ataxic with dyskinesia being further divided into Dystonia and Choreoathetosis. A mixed category is also available for those where no one motor disorder predominates ${ }^{16}$. This retrospective study has categorised children with $\mathrm{CP}$ according to the tone and movement disorder into spastic, dyskinetic, ataxic, pure hypotonic and dystonic variety. Those children who had more than one type of neuromotor activity were grouped in to the mixed category.

Of the 145 children with $\mathrm{CP}$ in this study, $93.1 \%$ had spasticity, $6.2 \%$ had dyskinesia, $2.8 \%$ had ataxia, $3.4 \%$ had pure hypotonia and only $1.4 \%$ had dystonia. Of the above cohort of children $11.7 \%$ had mixed pattern of cerebral palsy. On comparison, Vicki Mc Manus et al describes from "The Surveillance of CP in Europe (SCPE)" a collaboration of registries in $\mathrm{CP},(\mathrm{n}=9128)$ as $53.9 \%$ of the children with $\mathrm{CP}$ had bilateral spastic $\mathrm{CP}, 31 \%$ had unilateral $\mathrm{CP}, 6.6 \%$ were of the dyskinetic type and $4.1 \%$ had ataxia this proportion varied from $1 \%$ to $7 \% 17$. According to an article by Chitra $\mathrm{S} \&$ Nandini $\mathrm{M}$ spastic cerebral palsy was the commonest, accounting for $70-75 \%$ of all cases, dyskinetic $10-15 \%$ and ataxic less than $5 \% 2$. McHale DP et al found that Ataxic CP (hypotonic CP) was clinically observed in approximately 5-10\% of all cases of cerebral palsy, making it the least frequent form of $\mathrm{CP}^{15}$.
Analysis of the topographic involvement of the movement dysfunction of the study group revealed the following, $57.9 \%$ of the children had diplegia, $15.2 \%$ had tetraplegia, $11 \%$ had total body involvement, $10.3 \%$ had hemiplegia and only $5.5 \%$ had triplegia. Other studies found diplegia to be the commonest (30-40\%) followed by hemiplegia $20-30 \%$ and quadriplegia $10-15 \% 2$. In an analysis of 1000 cases of CP from North India by Singhi et al, spastic quadriplegia constituted $61 \%$ and spastic diplegia $22 \%{ }^{19}$. In the SCPE study the proportion of hemiplegic CP varied from $18 \%$ to $36 \%$ and diplegia from $13 \%$ to $55 \%^{16}$.

On analysis of the type of neuromotor abnormality against the topographic distribution the data from the present study revealed the following, $60.7 \%$ of the spastic type had diplegia, $11.9 \%$ had tetraplegia, $11.1 \%$ had hemiplegia and $10.4 \%$ had total body involvement.

According to Himmelmann $\mathrm{K}$ and colleagues, The prevalence of dyskinetic cerebral palsy appears to have increased in children with normal birth weight and $59 \%$ of them needed a wheelchair ${ }^{18}$. In this study $6.2 \%$ had dyskinesia and $55.6 \%$ of the dyskinetic type had total body involvement and 22.2\% had diplegia and $22.2 \%$ had tetraplegia. There were no triplegia or hemiplegia in the dyskinetic type. Hence one could hypothesize that dyskinetic CP could have a more global and bilateral topographic pattern of involvement. Of the children with ataxia half had tetraplegia and half had diplegia. $80 \%$ of the pure hypotonic categorywere tetraplegic. Dystonic category also had a global pattern of topographic involvement in that $50 \%$ had tetraplegia and another $50 \%$ had total body involvement. But that was only in two children with CP.

Most of the children with mixed pattern also had a global bilateral topographic pattern of involvement, $23 \%$ had tetraplegia, and $58.8 \%$ had total body involvement, only $11.8 \%$ had diplegia and $5.9 \%$ had triplegia.

When the patterns of CP was analysed based on the gender this study revealed the following $75 \%$ 
of the children with ataxia were females and $25 \%$ were males. Two children belonged to the dystonia category and both were females. There was a slightly more preponderance for females $(58.8 \%)$ than males $(41.2 \%)$ in the mixed type of $\mathrm{CP}$. However in the spastic type males had a preponderance $(60 \%)$ and females $40 \%$.

At the first visit for serial casting for the children in this study group $60 \%$ had received bilateral below knee casting, $21.4 \%$ received bilateral above knee casting, $7.6 \%$ received bilateral cylinder casting, $9.7 \%$ received below knee casting on one leg and two children received above knee casting on one leg. However when serial casting progressed there would have been a change in the type of casting applied to improve the functional mobility. Recording of this change was beyond the scope of this study.

This study revealed similar patterns of $\mathrm{CP}$ as in other studies as majority of the children had spasticity. However some had ataxia, hypotonia, and dyskinesia with about one tenth of the children having a mixed pattern. Interestingly $11 \%$ of the cohort had total body involvement.

\section{Conclusion}

Majority of the Children with cerebral palsy in this study who underwent serial casting belonged to the 2 to 6 age group, mean age was 5.8years.

More than half of the children in the study group were males.

Majority of the children with cerebral palsy in the study group had hypertonia (93.8\%) and only a few had hypotonia (6.2\%).

The proportion of clinical patterns of cerebral palsy in the study group were as follows, $93.1 \%$ had spasticity, $6.2 \%$ had dyskinesia, 3.4\% had pure hypotonia, $2.8 \%$ were ataxic, and only $1.4 \%$ had dystonia.

$11.7 \%$ of the study group had a mixed type of movement dysfunction.

Topographic distribution revealed that almost $58 \%$ had diplegia and interestingly $11 \%$ had total body involvement.
Almost all the children with hemiplegia had only spasticity.

More than $50 \%$ of the dyskinetic variety had total body involvement.

Almost all of the pure hypotonic type had involvement of all the four limbs.

Majority of the children with mixed features had involvement of all the four limbs or had a total body involvement.

Ataxia, hypotonia and dystonia were seen more in females.

\section{Limitations of the study}

The study cohort was limited to one tertiary care centre.

The assessment of movement dysfunction was recorded by different clinicians. When compared to other studies which looked into the general population of children with $\mathrm{CP}$ this study focused on those who received serial casting.

As incomplete forms and data of the subjects were discarded and only those with complete data were included in the study, some patterns may not have been represented adequately, and hence may not represent the true picture of distribution of the clinical patterns in the said population. Only the first visit of the child for serial casting was taken and so the type of casting received may not represent the total treatment received.

Further prospective or prevalence studies on this subject in the future could provide more information.

\section{Conflict of Interest: None \\ Source of Funding: None \\ Acknowledgement}

The authors thank Prof Dr Abdul Gafoor S for support and advice.

Dr. Oommen P. Mathew MSc, PG D (Com. Sc), PGD (Bio Stat), PhD (Demography)

Research Investigator, Population Research Centre, University of Kerala 


\section{References}

1. Rosenbaum $P$, Paneth N, Leviton A, Goldstein M, Bax M, Damiano D, et al. A report: the definition and classification of cerebral palsy April 2006. Dev Med Child Neurol Suppl. 2007;109:8-14.

2. Sankar C, Mundkur N. Cerebral palsydefinition, classification, etiology and early diagnosis. Indian $\mathbf{J}$ Pediatr. 2005;72(10):865-8.

3. Capute AJ, Accardo PJ, editors. Capute and accardo's neurodevelopmental disabilities in infancy and childhood v. 2; Spectrum of neurodevelopmental disabilities. 3rd ed. Baltimore, MD: Brookes Publishing; 2008.

4. Himmelmann $K$, Uvebrant $P$. The panorama of cerebral palsy in Sweden part XII shows that patterns changed in the birth years 2007-2010. Acta Paediatr. 2018;107(3):462-8.

5. Report of the Australian Cerebral Palsy Register Birth years 1995-2012. November 2018: 48. Table 22.

6. Dursun N, Gokbel T, Akarsu M, Dursun E. Randomized controlled trial on effectiveness of intermittent serial casting on spastic equinus foot in children with cerebral palsy after botulinum toxin-A treatment. Am J Phys Med Rehabil. 2017;96(4):221-5.

7. Chung K. Essentials of hand surgery. Chung KC, editor. London, England: JP Medical; 2015.

8. Bhimani R, Anderson L. Clinical understanding of spasticity: implications for practice. Rehabil Res Pract. 2014;2014:279175.

9. Watt J, Sims D, Harckham F, Schmidt L, McMillan A, Hamilton J. A prospective study of inhibitive casting as an adjunct to physiotherapy for cerebral-palsied children. Dev Med Child Neurol. 1986;28(4):480-8.
10. Novak I, McIntyre S, Morgan C, Campbell L, Dark L, Morton N, et al. A systematic review of interventions for children with cerebral palsy: state of the evidence. Dev Med Child Neurol. 2013;55(10):885-910.

11. Kelly B, MacKay-Lyons M, Ruggles T, Woodward J. Botulinum toxin type A and serial casting versus botulinum toxin type A or serial casting in treating equinus gait of children with cerebral palsy. Cochrane Libr [Internet]. 2008; Available from: http://dx.doi.org/10.1002/14651858.cd007 343

12. Blackmore AM, Boettcher-Hunt E, Jordan M, Chan MDY. A systematic review of the effects of casting on equinus in children with cerebral palsy: an evidence report of the AACPDM. Dev Med Child Neurol. 2007;49(10):781-90.

13. Teplicky R, Law M, Russell D. The effectiveness of casts, orthoses, and splints for children with neurological disorders. Infants Young Child. 2002;15(1):42-50.

14. Jain S, Mathur N, Joshi M, Jindal R, Goenka S. Effect of serial casting in spastic cerebral palsy. Indian J Pediatr. 2008;75(10):997-1002.

15. McHale DP, Jackson AP, Campbell, Levene MI, Corry P, Woods CG, et al. A gene for ataxic cerebral palsy maps to chromosome 9p12-q12. Eur J Hum Genet. 2000;8(4):267-72.

16. Surveillance of Cerebral Palsy in Europe. Surveillance of cerebral palsy in Europe: a collaboration of cerebral palsy surveys and registers. Surveillance of Cerebral Palsy in Europe (SCPE). Dev Med Child Neurol. 2000;42(12):816-24.

17. McManus V, Guillem P, Surman G, Cans C. SCPE work, standardization and definition--an overview of the activities of SCPE: a collaboration of European CP registers. Zhongguo Dang Dai Er Ke Za Zhi. 2006;8(4):261-5. 
18. Himmelmann K, McManus V, Hagberg G, Uvebrant $\mathrm{P}, \mathrm{Kr}$,geloh-Mann I, Cans C, et al. Dyskinetic cerebral palsy in Europe: trends in prevalence and severity. Arch Dis Child. 2009;94(12):921-6.

19. Singhi PD, Ray M, Suri G. Clinical spectrum of cerebral palsy in north India-an analysis of 1,000 cases. J Trop Pediatr. 2002;48(3):162-6.

20. Colledge N. A guide to cerebral palsy . The Ontario Federation for Cerebral palsy.2011:7-8.

21. Report of the Australian Cerebral Palsy Register Birth years 1995-2012. November 2018: 30 . 